\title{
Massive Forest Fires and Mitigating Stratigies in New Arena: A Case Study
}

\author{
Sonakshi Saxena* \\ Department Of Economic \\ Chaudhary Charan Singh (CCS) \\ University, Meerut (UP)
}

\begin{abstract}
This research paper is a case study of Massive forest fires and Mitigating Strategies in New Arena. This paper helps to identifies the resources that need to be redirected to prevent forest fires and also to identifies existing management practises that encourage harmful fires and promote management systems that mimic natural fires regime. This paper was reviewed and explained with the help of secondary data available through various journals , magazines, government publications, previous research papers and other useful internet materials. Paper presents and attempts to study, the resources that need to be redirected to prevent forest fires and also to identifies existing management practises in India, Australia, and Russia.
\end{abstract}

Keywords- Massive Forest Fires,Uttarakhand, globally, Temperature, siberia.

\section{INTRODUCTION}

Food And Agriculture organisation (FAO), 'land with a tree canopy cover of more than 10 percent and area of more than 0.5 hectares.' Forest fires are the growing issue in new arena. Throughout the world, forest fires are out of control. Many millions of hectares are burnt in the last three decades, affecting health and livlihoods. Globally, most forest fires are probably now directly or indirectly influenced by humans and climate change. The world has two problems with fires : an increase in unwanted fires and a parallel reduction in necessary fires. Conversely, each year many natural or beneficial fires are suppressed, which with have negative impact over the long term.

\begin{tabular}{|l|r|}
\hline \multicolumn{1}{|c|}{ State/UTs } & \multicolumn{2}{|c|}{ Forest Fire Points } \\
\hline Sikkim & 28 \\
\hline Tamil Nadu & 2,067 \\
\hline Telangana & 11,643 \\
\hline Tripura & 9,603 \\
\hline Uttar Pradesh & 5,483 \\
\hline Uittarakhand & 6,665 \\
\hline West Bengal & 1,783 \\
\hline TOTAL & $\mathbf{2 , 7 7 , 7 5 8}$ \\
\hline
\end{tabular}

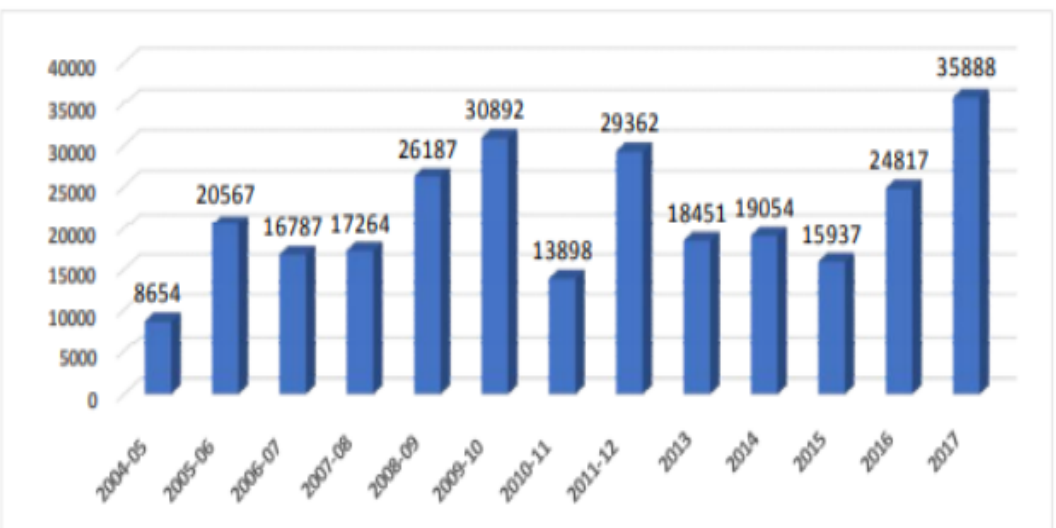

Now let's consider massive forest fires in different countries. 


\section{REVIEW OF LITERATURE}

1. Peter Moore, Jeff Hardesty, Stephen Kelleher, Stuart Maggins on their paper ' Forest and wildfires : fixing the future by avoiding the past' stated, each year wildfires destroy 6 to 14 millions hectares Of fire sensitive forests worldwide, a rate of loss and degradation comparable to that of destructive logging agricultural conversion. Those areas that are hot and dry for part of each year, where frequent fires would be expected, human influence has now become so pervasive.

2. Muchkund pant, Vinay purohit on their paper ' Forest fire - A case study on four national parks of Uttarakhand'. Uttarakhand is an Himalayan state which holds a large number of species of wild flora and fauna. Uttarakhand has $45.32 \%$ of its geographical area under the forest cover. Each year witnesses a large number of forest fires.

\section{OBJECTIVES}

1. TO identifies the resources in different countries that need to be redirected to prevent forest fires.

2.To identifies existing management practises in India, Australia, and Russia that encourage harmful fires.

3. To evaluate the management systems that prevent natural fire regime.

\section{RESEARCH METHODOLOGY}

The current study attempts to explain the Massive Forest fires in different countries in new arena and also examine the management practises that encourage harmful fires, identifies the resources that need to be redirected, and evaluate the management systems that mimic natural fires.

The nature of research is completely descriptive. It is conceptual research which is based on review of previously researches in this area. All the relevant data used in research paper has been collected from secondary sources e.g. e-journals, newspapers, and various other internet resources.

\section{Forest fires in India}

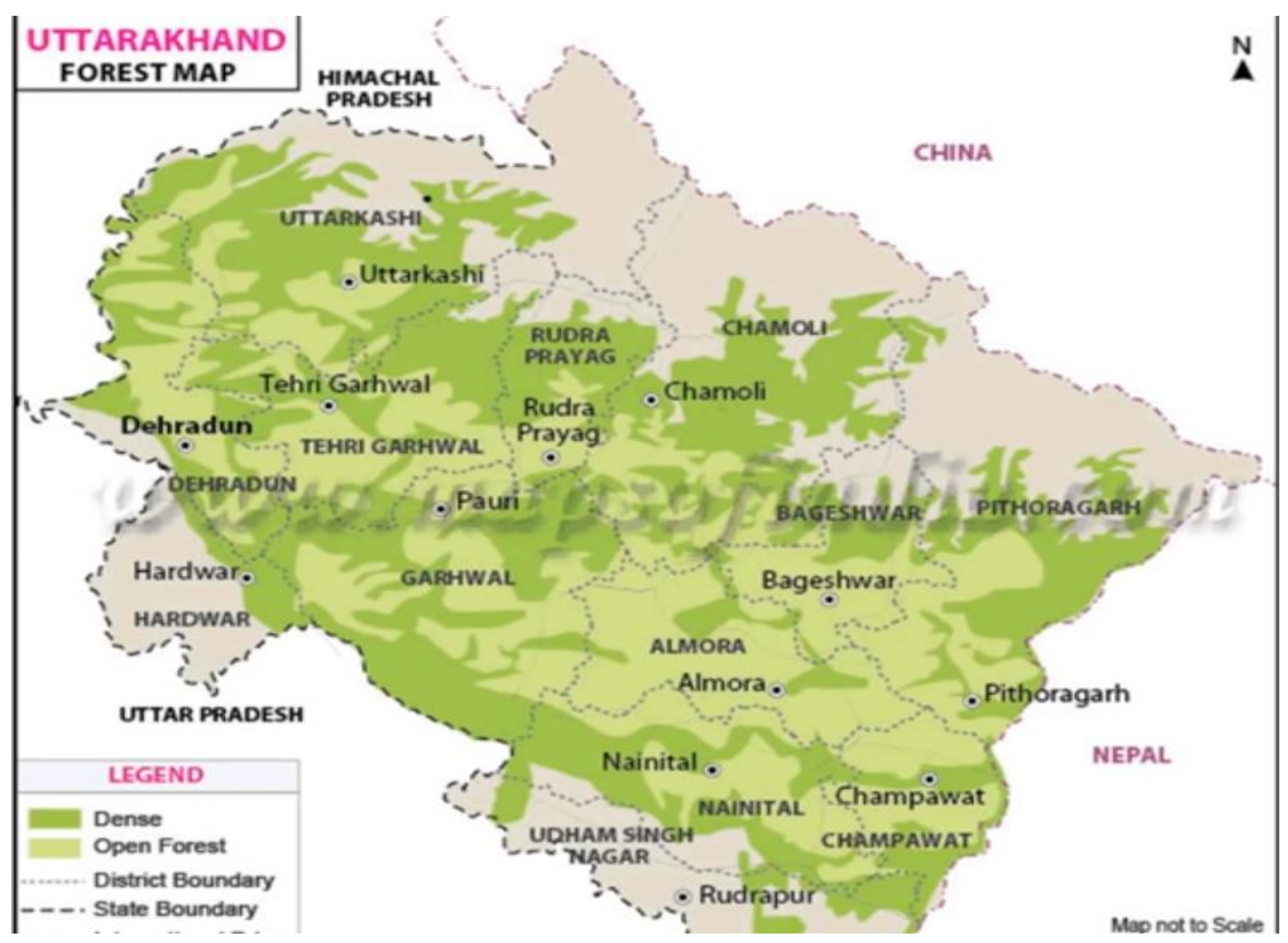

Source :Forest Survey Of India

Graphical representation showing the total forest fires in 13 years

According to India State of forest report 2019, over 30,000 incidents of forest fires were reported in india in 2019. Additionally, more than $36 \%$ of indian forest cover (657, 000 square kilometers) area is prone to frequent forest fires and of this, $10 \%$ are highly prone according to Forest Survey Of India (FSI) report on forest fire prone forest areas. 


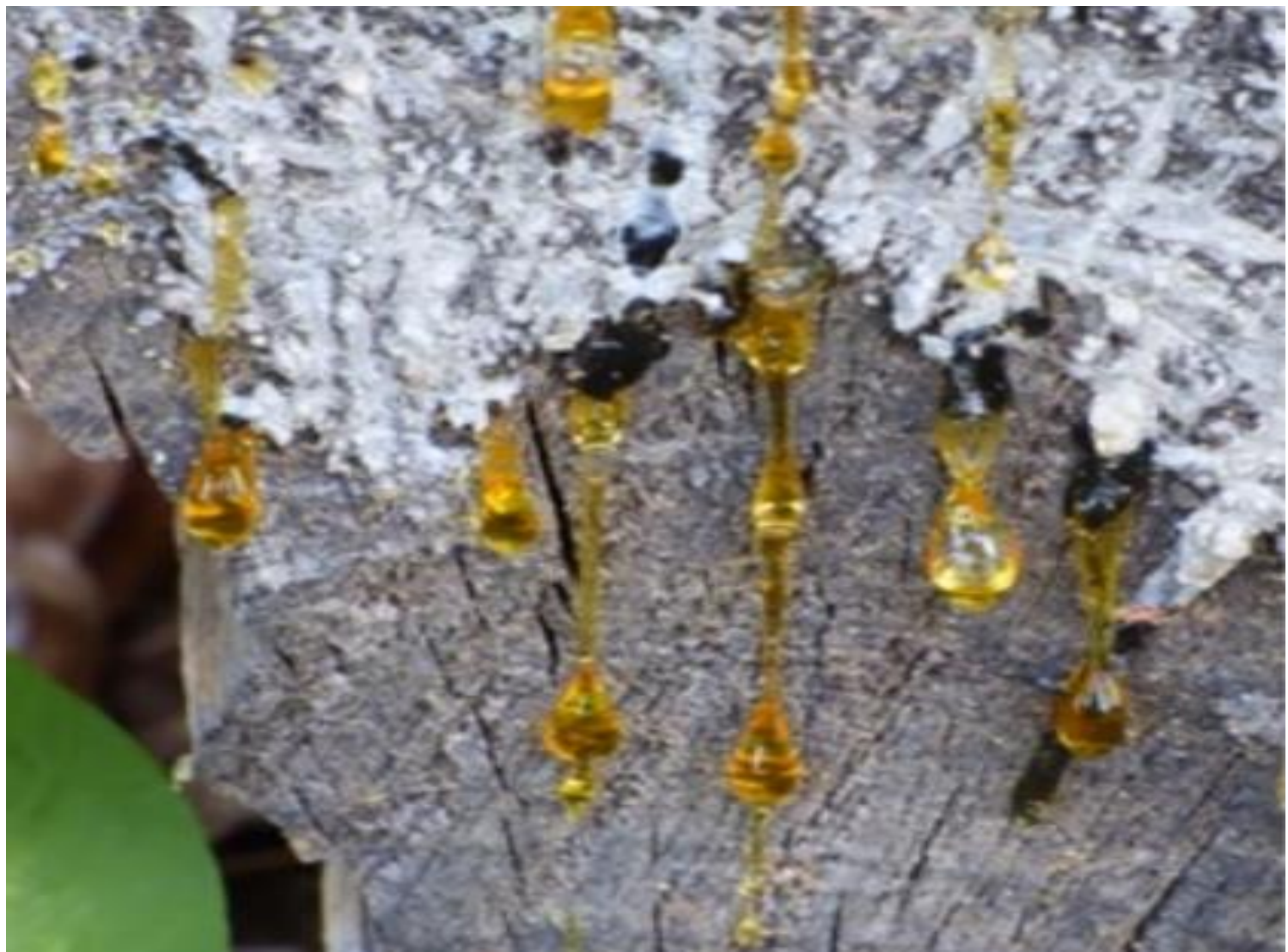

\section{Source: Internet}

Uttarakhand is an Himalayan state which holds a large number of species Of wild flora and fauna. Every year Uttarakhand witnesses a large number of wild fires i.e. 20 fires in four days, recently. Kumaon Division is the most common zone of forest fires. The most common reason of forest fires, as the temperature in Uttarakhand continue to rise and reduced percipitation due to climate change in large parts of the hills state are under raging fire. According to a report, In 2020 the area under forest fires reached 20,377.77 hectares, which is 793 hectares more than the land impacted by forest fires last years.

Sap from pine trees

Presence of pine trees in most of the areas is also one of the main reason for forest fires. Pine trees produced a lot of sap, also known as rosin, which is highly flammable and burns very hot.

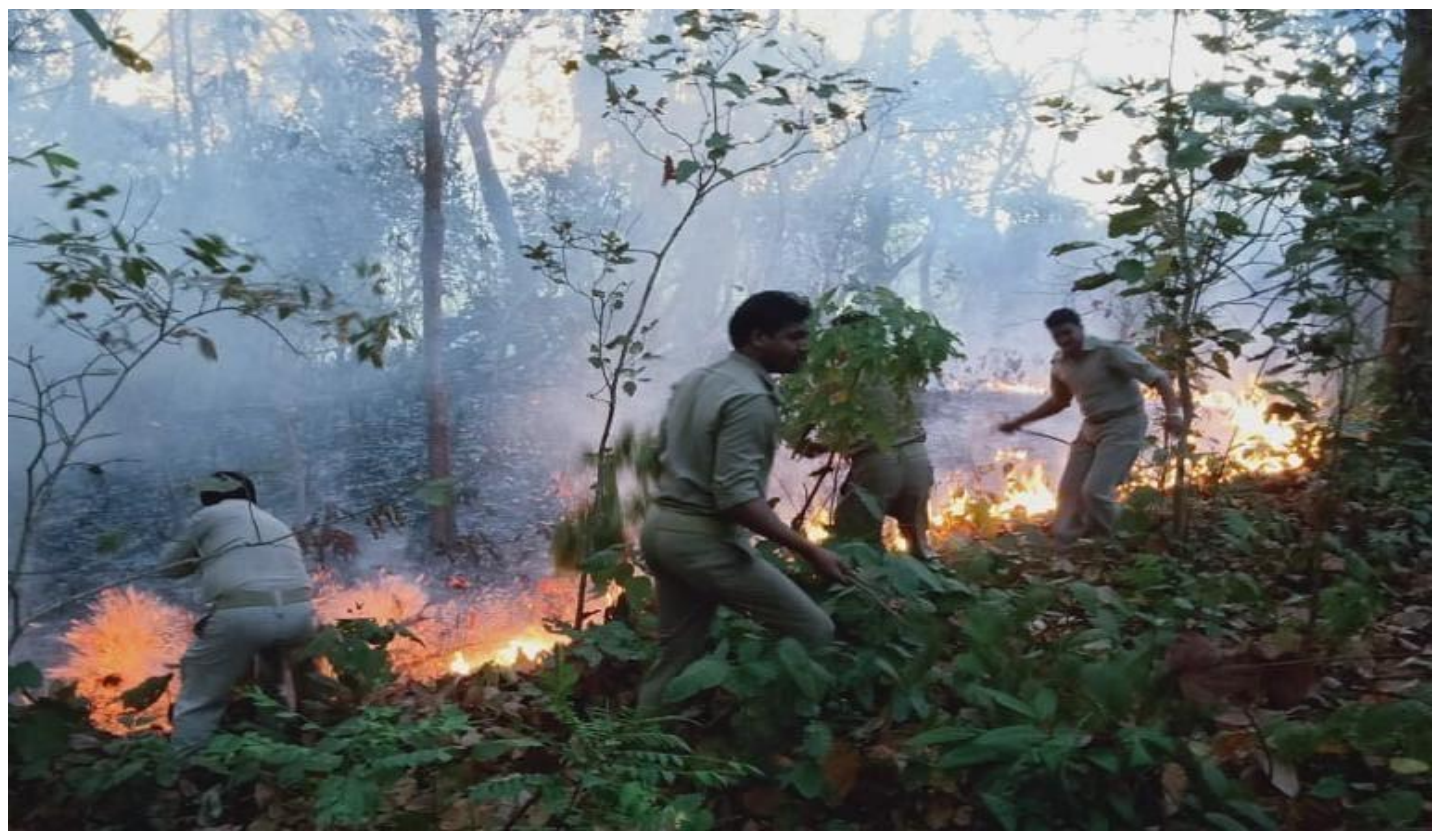




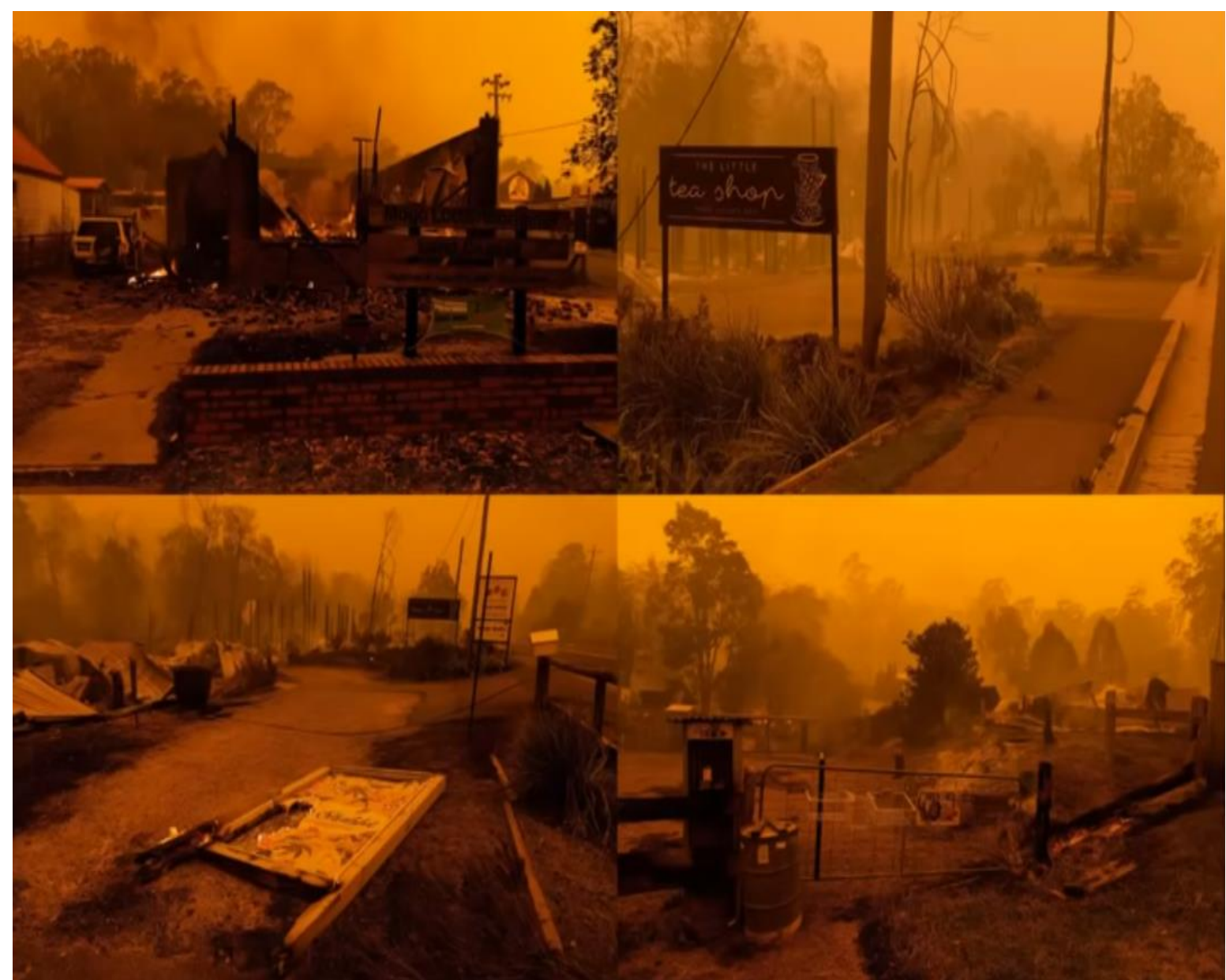

The Chief conservator of forest has been set up but it has remained as thoothless tiger. It was created to fight forest fires after devastating blaze in the year 2016.

A former official who held the position told that, " I had no power to make budgetry allocations, intimate surveys or research. Forest fires management needs statewide long-term policies, but there was noprovision for that ". The Forest Drone Force is also stretchef thin.

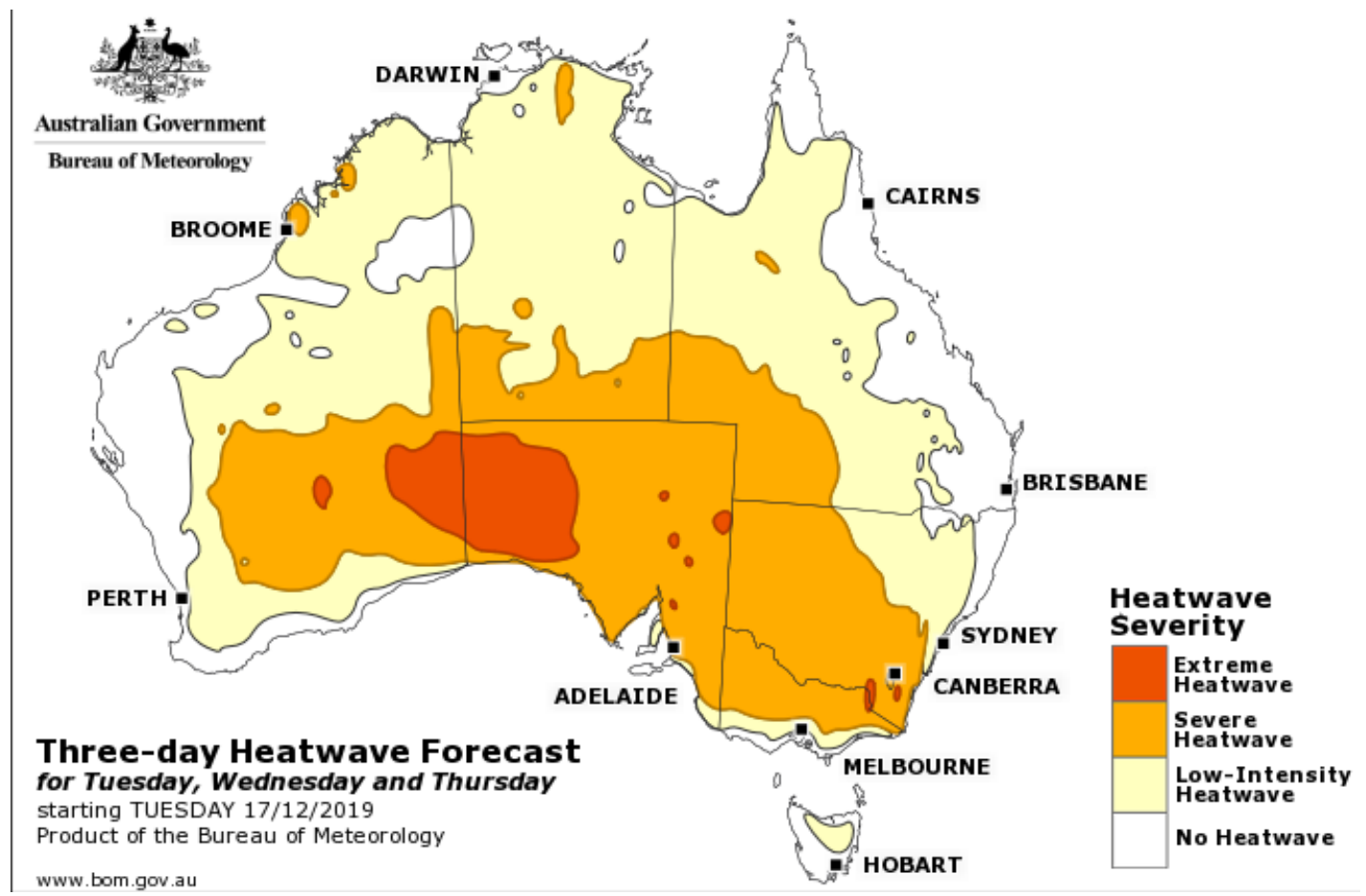




\section{Forest fires in Australia}

A bushfire burns out of control in Namadgi National Park.

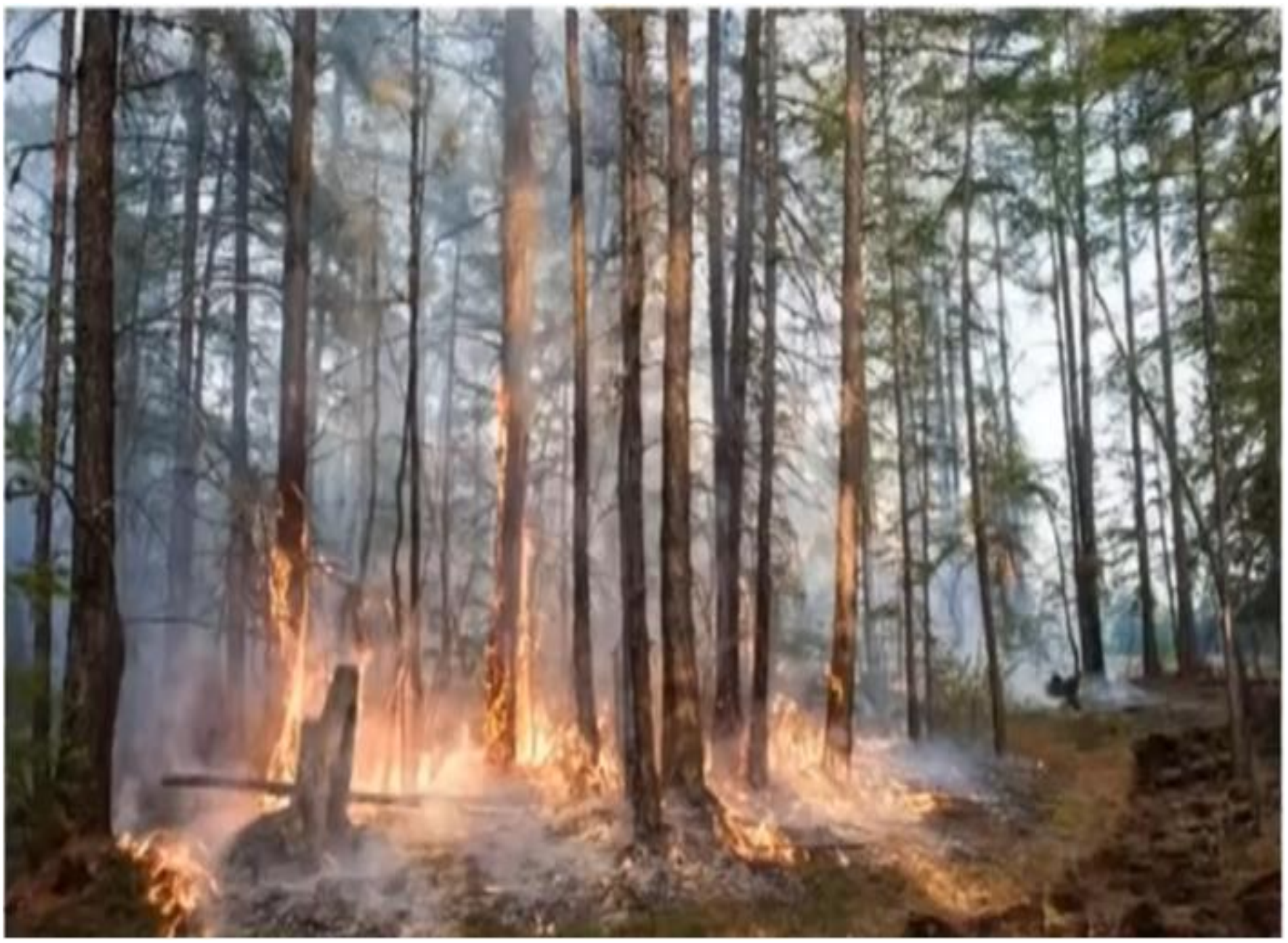

Source :internet

CANBERRA FOREST FIRES (2020)

A bushfire burns out of control in Namadgi National park. The fire strated from remote bushland in rugged terrain that is inaccessible to ground crews. The fire is threatening the town of Tharwa, South of Canberra.

Bushfire are expected to creep dangerous close to canberra. Source: internet

Australia's deadly fires have been fuelled by a combination of extreme heat, prologed drought and strong winds. The country is in the grip of heat wave, with record-breaking temperature over the last years. The Bureau of Meterology data shows average temperature record across the country beat previous high of 2013. The year 2019 was the hottest on record for Australia with the temperature reading 1.52 degree Celsius above the long term average.

Canberra massive bushfire (2020)

source:internet

The main reason of such massive fires can be, all the follows the country's driest spring since record began 120 years ago, with much of New South Wales and Queensland experiencing rainfalls short since early 2017. Trees, shrubs and grasslands have turned into the perfect tinder for flame.

\section{Forest fires in Russia}

\section{SIBERIA FOREST FIRES (2020)}

Wildfires in siberia have burned down an area larger than Greece- CBS News

With the area of 13.1 milion square kilometers. Siberia makes up roughly $77 \%$ of Russia's total territory and almost $9 \%$ of earth's surface.

The climate of siberia varies drastically, but it typically has short summers and long, brutally cold winters.

Vegetation in Siberia is mostly taiga, with a tundra belt on the Northern fringe, and a temperate forest zone in the South heat wave is blowing. Siberia has been experiencing extreme heat due to a combination of persistent sunny weather and human caused climate change. 
The has has broken many temperature records. In the 1st six months of 2020, Siberia experienced a period of unusually high temperatures, including a record-breaking 38 degree Celsius in the town of Verkhoyansk.

The total area burnt by wildland fires in Russia sincethe beginning of 2020has reached 19 million hectares. (Greece). The fire started to spread across Siberian forests around the midfle of june. The following factors have caused the fires to spread aggressively -extreme dry ground, hotter than average temperature, heat lightning, strong winds.

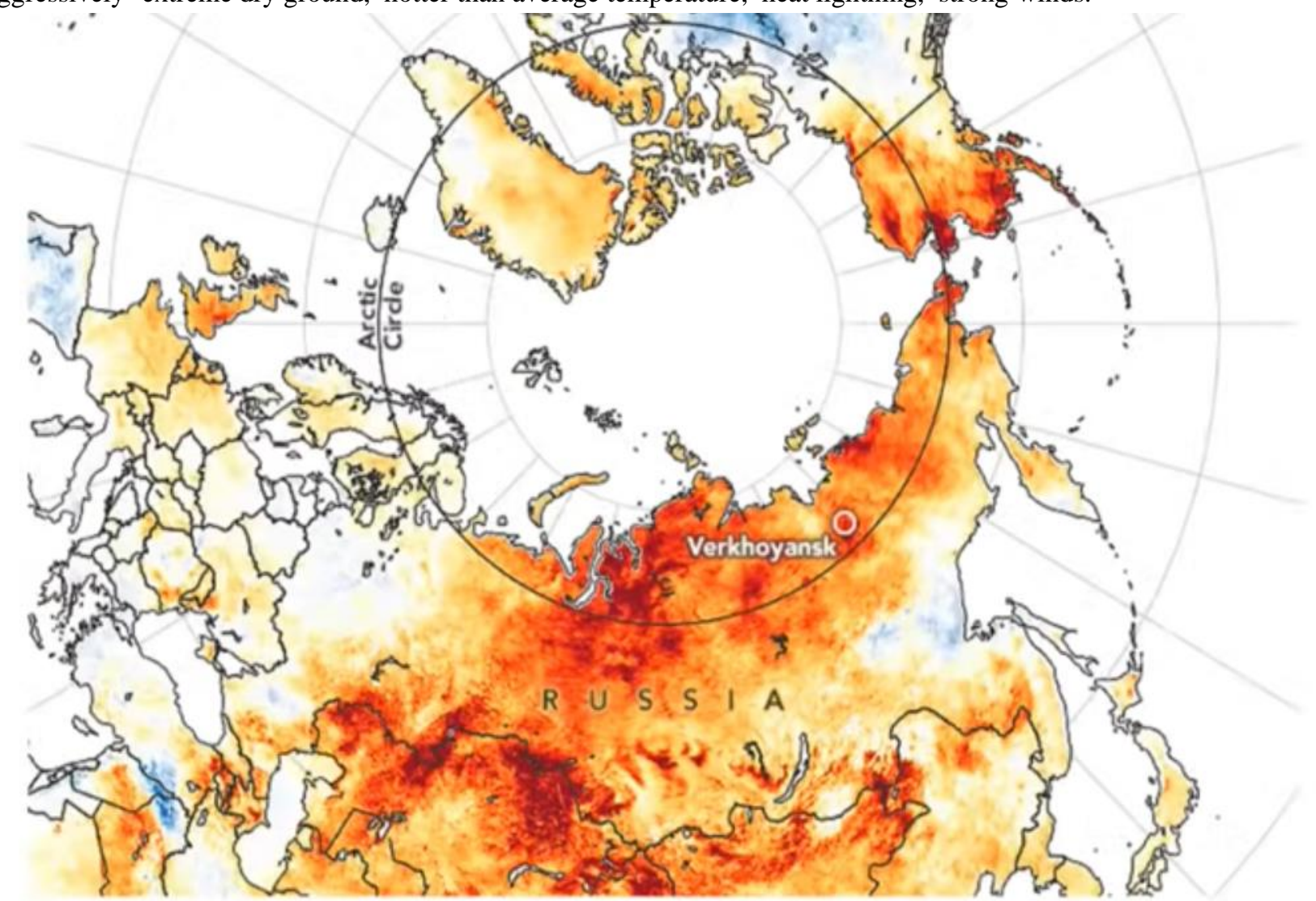

Land Surface Temperature Anomaly (difference from 2003-2018 Spring average, ${ }^{\circ} \mathrm{C}$ )

$$
\text { ) }
$$

Massive forest fire in Siberia(2020)

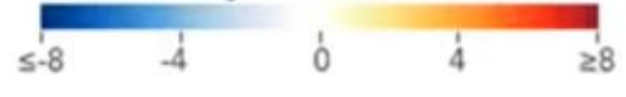

\section{CONCLUSION OF THE STUDY}

Forest fires are caused by extreme weather not necessarily true. Globally, most forest fires are probably now directly or indirectly influenced by humans. Human set fires, not least because it is cheap and simple land management tool, and for poorer people or smallholders the only option. Those areas that are hot and dry for part of each year, where frequent fires can be expected, human influence has now become so pervasive the most fires are -unnatural. Mitigation techniques seemed to have had little or no effect at all. Unplanned development has also affected the forest fires.

\section{SUGGESTIONS}

1. Identification and Mapping of all fire prone areas.

2. Compilation and analysis of data base on the damage due to forest areas .

3. Installation of Forest Danger Rating systems anf Fire forcasting systems.

[1] The Times Of India, reported on May 24, 2020.

\section{REFERENCE}

[2] State forest department of Uttarakhand

[3] 9NEWS reported on january 2, 2020

[4] Bureau of Meterology

[5] CBS NEWS

[6] World weather Attribution

[7] International NGO Green peace

[8] Peter Moore, Jeff Hardesty, Stephen Kelleher, Stuart Maggins on their paper ' Forest and wildfires : fixing the future by avoiding the past'.

[9] Muchkund pant, Vinay purohit, (2019) on their paper ' Forest fire - A case study on four national parks of Uttarakhand'. 